\title{
Examination of OECD Countries for the Presence of Livestock by Non-Metric Multidimensional Scaling
}

\author{
Yıldırım Demir ${ }^{1, *}$ (D), Sıddık Keskin ${ }^{2}$ \\ ${ }^{1}$ Department of Statistics, Faculty of Economics and Administrative Sciences, Van Yuzuncu Yil University, Van, Turkey. \\ ${ }^{2}$ Department of Biostatistics, Faculty of Medicine, Van Yuzuncu Yil University, Van, Turkey.
}

\section{Article History}

Received: 15 Mar 2021

Accepted: 29 Jun 2021

First Online: 15 Sep 2021

\section{Corresponding Author* \\ Tel.: +90 4322251701 / 27641 \\ E-mail: ydemir@yyu.edu.tr}

\author{
Keywords \\ Distance \\ Stress \\ Dimension reduction \\ Configuration \\ Similarity
}

\begin{abstract}
In this study, by Non-metric multidimensional scaling (NMDS) which is one of the multivariate statistical analysis methods, configuration of 36 OECD countries in two dimensional space was examined and similarities/dissimilarities between these countries were determined for the variables regarding with livestock data. As variables, "number of horses, pigs, donkeys, turkeys, mules, geese, goats, sheep, buffaloes, ducks, cattle and chickens" of OECD countries obtained from the website of FAO was used. Euclidean distance was used as distance measures. According to the results of NMDS; USA, Germany, France, England, Canada and Poland had the highest positive effect on livestock. However, Israel, Iceland, Lithuania and Luxembourg were different from other countries with the lowest effects. Similarly, while buffalo was the lowest effective one; pigs, cattle, chicken and turkey were found the highest effective species on the livestock sector. As a result, it was suggested that NMDS can be used as an effective method in the analysis of multivariate data in agriculture and livestock with simple graphical representation and interpretation of the results.
\end{abstract}

\section{Introduction}

The steady increment in the world population lead to increase importance of animal production. Therefore, properly plans and policies should be developed by obtaining information about animal assets and acting consciously about animal science. According to Food and Agriculture Organization of the United Nations in 2018, There are 1786881743 cattle (buffalo, cattle), 2557846061 ovines (sheep, goat), 123687495 single-hoofed (horse, donkey, mule), 1425 507453 pig, 32041935000 poultry (chicken, turkey, duck, goose) in 36 OECD countries (FAO, 2020). In the light of these data, it can be stated that OECD countries has approximately $17.17 \%$ of world animal wealth. Turkey is placed considerable point among the OECD countries.

Some studies (Ersöz, 2008; Beyhan Acar, 2013; Boz et al., 2016; Akdamar, 2019) have been carried out to identify similarities or dissimilarities between OECD (Organization for Economic Co-operation and Development) countries with Multidimensional scaling (MDS). Akın and Eren (2012) examined the similarities or dissimilarities of OECD countries for education indicators. Furthermore, by using MDS, Çelik (2015) classified Turkish provinces for livestocks.

In the scientific research, as the number of variables increases, the number of dimensions also increases. Thus, there are some difficulties in interpreting of the results obtained. To overcome these difficulties, multivariate statistical methods, especially dimension reduction methods are used and the results are more easily interpreted and understandable by using two or three dimensions instead of multiple dimensions. Therefore, multivariate statistical methods play an important role in statistics and are used in almost all disciplines. These methods examine the relationships between two or 
more dimensional variables by considering together. As a one of multivariate statistical methods, MDS examine the data in a smaller scale (Ağgün, 2011; Härdle and Simar, 2015).

MDS is a graphical method that allows determining the relationship between objects by displaying in kdimensional space as close as possible for their real positions and a less dimensional space by using distance values in cases where the relationships between objects are unknown however computable (Johnson and Wichern, 2007; Özdamar, 2010; Alpar, 2011). The purpose of the graphical representation method is to transform the relationships between objects or variables into a more understandable form (Borg and Groenen, 2005). The application area of MDS is quite common due to using the similarities measures instead of distance or difference measures. MDS can be applied to both metric and non-metric variables in various scientific fields such as Psychology, Sociology, Education, Agriculture, Economics, Marketing, Medicine and Engineering (Tatlıdil, 1992; Ding, 2018).

Multivariate statistical methods such as Principal Component Analysis, Factor Analysis, Correspondence Analysis and Cluster Analysis can be used similar purposes. However, these methods require large sample size as well as some assumptions. MDS can be considered to more advantageous than these multivariate statistical methods due to more flexible for assumptions and small sample size. High-dimensional (multivariate) data sets are quite common in many fields of science, especially, animal science. Thus, MDS can be used effectively to examine the relationships between variables in terms of similarities or dissimilarities.

With this perspective, the aim of this study is to explain MDS briefly and to examine similarities or dissimilarities of OECD countries in terms of livestocks and to present configuration of the countries in twodimensional space for easy understanding and interpretation.

\section{Materials and Methods}

Material of the study consists of number of animals for 36 OECD countries in 2018 (FAO, 2020). Totally 12 variables that horse, pig, donkey, turkey, mule, goose, goat, sheep, buffalo, duck, cattle, and chicken numbers were included into analysis.

In the study, NMDS was used to statistical analysis method. This analysis determines the similarities or dissimilarities between $\mathrm{n}$ points and shows the distances between these points in a reduced dimensional space with the help of appropriate distance measures (Johnson and Wichern, 2007; Özdamar, 2010).

MDS can be summarized in 6 steps:

- In case of different scaled variables, these variables are converted into a standard scale for equal effect in determining the distance.

- Using the appropriate distance measurement for the data type, the $n x n$ dimensional distance matrix is calculated.
- To display objects in reduced dimensional space, stress value (statistic) that is measure of fit is computed for determination of reduced dimension number.

- According to data type, properly regression method such as linear, polynomial or monotonic regression is performed to calculate original $\left(\delta_{\mathrm{ij}}\right)$ and configuration distances $\left(d_{i j}\right)$ of objects.

- The stress value which is a suitable statistic is calculated to determine the fit original and configuration distances.

- To display distances of objects in reduced dimension, coordinates of the objects are determined. Positions of each object are displayed in the determined coordinates or 2 dimensional space (Özdamar, 2010).

In order to reduce the number of dimensions, the configuration distance $\left(\mathrm{d}_{i j}\right)$ values represented in the new space are used instead of the similarity measures $\left(\delta_{i j}\right)$ Thus, the configuration distances are accepted to be equal to the original distances and estimated distances of them are shown with $\hat{d}_{i j}$ (Tatlıdil, 1992; Härdle and Simar, 2015).

MDS is based on the distance measures. Therefore, similarities or dissimilarities between the objects are computed by using the distance functions. According to the data structure and variable type, various distance measures are recommended. Therefore, it is very important to use the appropriate distance measure. Euclidean distance is quite common distance function in MDS (Everitt and Dunn, 2001; Özdamar, 2010). Euclidean distance is used to determine the distance between two points. It can also be used to determine the distances of elements on a data matrix. Thus, using the generalized Euclidean distance equation, the configuration distance between $\mathrm{i}^{\text {th }}$ and $\mathrm{j}^{\text {th }}$ points in a $\mathrm{p}$-dimensional is follows.

$$
d_{i j}=\left[\sum_{a=1}^{p}\left(x_{i a}-x_{j a}\right)^{2}\right]^{1 / 2}(\mathbf{1})
$$

In the equation (1), $x_{i a}$ and $x_{j a}$ give the $\mathrm{i}^{\text {th }}$ and $\mathrm{j}^{\text {th }}$ observation values in $a^{\text {th }}$ and $a^{\text {th }}$ dimension, respectively. Thus, the distance between the elements of the data matrix can be computed in twodimensional space (Cox and Cox, 2001; Everitt and Dunn, 2001).

In MDS, number of distances between $n$ objects is computed with $[n(n-1) / 2]$. These distances are symmetrical and known as configuration distances. In order to obtain a low dimensional geometric representation, a coordinate system is tried to be created by obtaining the closest viewing distances to the configuration distances. The distances are calculated with the metric scaling method in case of interval or ratio scaled variables. However non-metric scaling method is used to ordinal scaled variables (Mackay and Zinnes, 1986; Mead, 1992).

Metric MDS uses directly for distance values to 
locate a given observation. However, non-metric MDS uses orders of magnitude instead of numerical values of distances, and the only information used in determining the display distances $\left(\hat{d}_{i j}\right)$ is the sequence numbers of the configuration distance $\left(d_{i j}\right)$ values in this analysis (Kruskal and Wish, 1978; Mead, 1992). Here, it is aimed that the distance values $\hat{d}_{i j}$ keep the same monotone increasing order relationship with the corresponding $d_{i j}$ values and scaling accordingly. Iteration method is used to minimize the stress value due to no analytical solution for the method. When the smallest stress value is obtained, iteration process is stopped and the size number is decided (Cox and Cox, 2001; Seber, 2004). NMDS is more preferred than metric MDS due to its more flexible assumptions and providing less dimensional solutions (Özdamar, 2010).

The efficiency of MDS is measured by STRESS (Standardized REsidual Sum of Squares) and the Stress value show the discrepancy between original and configured distances of objects (Kruskal and Wish, 1978). In general, Kruskal stress statistic is used in NMDS. The first reason for this is that this statistic has been widely accepted, and the other is that the statistics can be calculated for good and weak NMDS solutions (Borg et al., 2018). Kruskal stress statistics is calculated by the following equation.

$$
\text { Stress }=\sqrt{\frac{\sum_{i<j}\left(d_{i j}-\hat{d}_{i j}\right)^{2}}{\sum_{i<j} d_{i j}^{2}}}
$$

In equation (2), $\left(\mathrm{d}_{i j}\right)$ shows the configured distance between $\mathrm{i}^{\text {th }}$ and $\mathrm{j}^{\text {th }}$ points, and the projection distance estimated by $\mathrm{c}^{\text {th }}$ iteration between $\mathrm{i}^{\text {th }}$ and $\mathrm{j}^{\text {th }}$ points according to $\hat{d}_{i j}$ multidimensional scaling. This value varies depending on the number of dimensions and scale used (Kruskal, 1964; Mead, 1992; Borg and Groenen, 2005; Johnson and Wichern, 2007). There are different versions of this given stress statistic in practice, such as the "Quadratic stress (S-stress) statistic" (Borg et al., 2018). The S-stress statistic is derived from the stress scale to reveal the mismatch between the assumed and original structures. S-stress statistics is calculated by the following equation;

$$
S-\text { Stress }=\sqrt{\frac{\sum_{i<j}\left(d_{i j}^{2}-\hat{d}_{i j}^{2}\right)^{2}}{\sum_{i<j} d_{i j}^{4}}}
$$

Alternating least squares scaling (ALSCAL) algorithm in SPSS program uses s-stress value (Giguère, 2006; Johnson and Wichern, 2007).

Dimensional solutions that give stress value close to 0 are specified as the most suitable or desired solution (Ersöz, 2008). For easy interpretation, the solution is desired to be smaller than four dimensions and generally, two dimensions are preferred (Mackay and Zinnes, 1986; Özdamar, 2010).
According to Kruskal-Shepherd tolerance rate, stress values can be classified as bad for $\sigma \geq 0.20$, medium for $0.1 \leq \sigma<0.20$ and good for $0.05 \leq \sigma<0.10$. If stress value is less than 0.025 , this indicated that there is a perfect fit between original and configured distances (Kruskal, 1964; Seber, 2004).

Another criterion is $\mathrm{R}^{2}$ and this is square of the correlation coefficient (Cox and Cox, 2001; Alpar, 2011). $R^{2}$ can be written as follows.

$$
R^{2}=1-\frac{\sum_{i=1}^{n}\left(d_{i j}-\hat{d}_{i j}^{2}\right)^{2}}{\sum_{i=1}^{n}\left(d_{i j}-\bar{d}\right)^{2}} \text { (4) }
$$

Where $\bar{d}$ is the average of the configured distances. If the value of $R^{2}$ is greater than $60 \%$; this is stated that the fit is reasonable and NMDS can be applied to the data (Alpar, 2011; Çelik, 2015). Thus, by using the ordinal numbers of the observed objects, coordinates of the points in space are obtained by NMDS (Cox and Cox, 2001).

Besides, another method used to determine the appropriate number of dimensions for the positions of objects in space is the scree plot. Scree plot shows the relationship between the stress value and the number of dimensions, and the number of dimensions is determined according to the breaking point expressed as elbow (Johnson and Wichern, 2007). In a scree plot, the curve usually decreases monotonous, however gradually there is a decrease in the slope such that it becomes fixed after a point. Elbow point of this curve determines number of dimensions (Borg and Groenen, 2005).

For MDS, ALSCAL algorithm is available in the IBM SPSS v21 statistical package program PROXSCAL algorithm for the scree plot is used (IBM Corp. Released, 2012). In addition, Euclidean distance is taken as a measure of distance.

Developed by Takane et al. (1977) to calculate optimal distances between objects in k-dimensional space, ALSCAL is the first applicable algorithm for MDS in non-metric individual differences. This algorithm minimizes the S-stress loss function (Equation (3)) with the least-squares method. ALSCAL represents large differences better than small differences and can be defined as a flexible MDS algorithm that provides models for asymmetric data, propagation and threeway analysis (Borg and Groenen, 2005).

\section{Results and Discussion}

The similarities and dissimilarities of 36 OECD countries in terms of the numbers of animals (horse, pig, donkey, turkey, mule, goose, goat, sheep, buffalo, duck, cattle and chicken) were analyzed. The scree plot is given in Figure 1.

Figure 1 shows that the change in stress values after the second dimension is very small and this is less 
than 0.025 at this point. Thus, it can be stated that two dimensions are suitable for visualizing the objects. Stress values showing the fit between the positions of these data in multidimensional space and their positions in two-dimensional space are given in Table 1.

Table 1 shows that the iteration was continued until the proper value of the stress. For two dimensions $(p=$ 2 ), iteration was stopped when stress value reached 0.00039 in the $4^{\text {th }}$ iteration. In the $4^{\text {th }}$ iteration, stress value was found 0.14790 and this value shows that the fit between the real positions of the data in the multidimensional space. Stress value can also be calculated by the Kruskal equation and the coefficient of determination, which is the square of the correlation coefficient, was given in Table 1. According to Kruskal equation, stress value was 0.13795 and this value indicated that fit is at a "moderate level". Corresponding to this stress value, determination coefficient $\left(R^{2}\right)$ was found 0.91107 . This value is

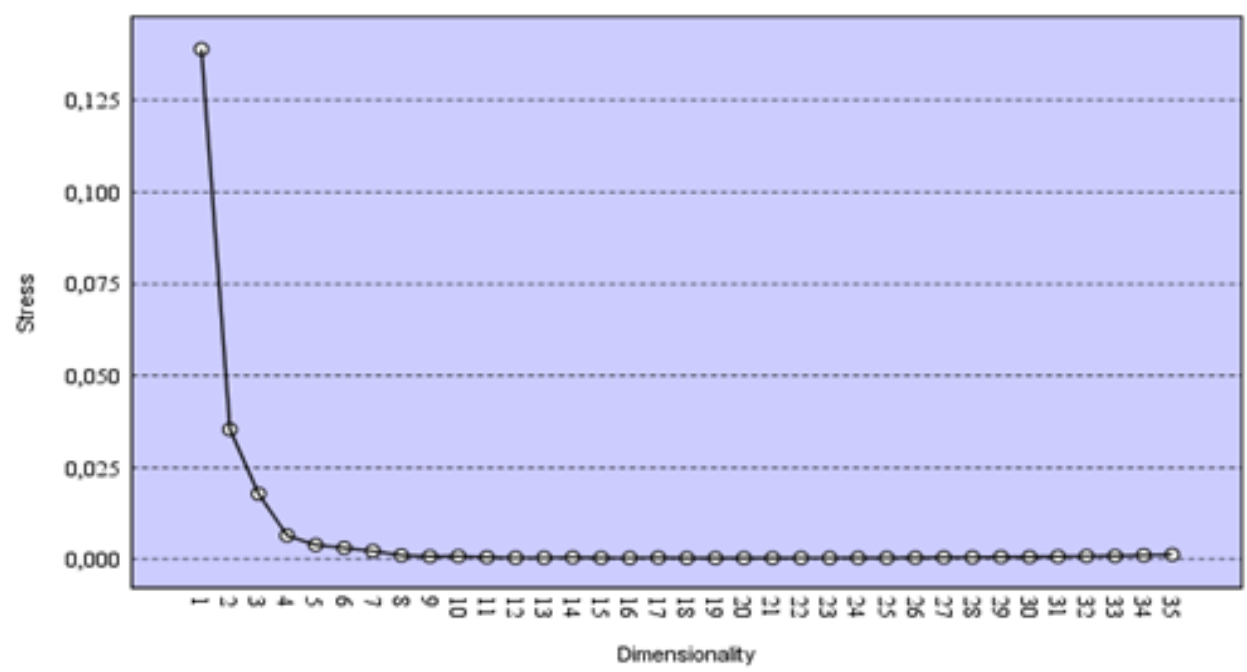

Figure 1. Scree plot showing the relationship between stress and dimension for countries.

Table 1. S-Stress, correction values and Kruskal Stress and $R^{2}$ value for two dimensions.

\begin{tabular}{ccccc}
\hline Iteration & S-tress & Improvement & Stress & $R^{2}$ \\
\hline 1 & 0.18849 & - & & \\
2 & 0.15100 & 0.03749 & 0.13795 & 0.91107 \\
3 & 0.14829 & 0.00270 & & \\
4 & 0.14790 & 0.00039 & & \\
\hline
\end{tabular}

greater than $60 \%$ and it indicates that the analysis is reliable.

Coordinates of the countries in two-dimensional space are given in Table 2.

According to the coordinates given in Table 2, locations of the countries in two-dimensional space were visualized in Figure 2. It can be stated that as the distance between objects decreases, the objects begin to look alike. However, as increasing of this distance, the objects begin to differ from each other. In other words, more similar countries are closely located each other on the graph (Çelik, 2015; Ding, 2018).

Table 2. The coordinates of the countries in two-dimensional space.

\begin{tabular}{lrrlrrlrr}
\hline Variable & 1.Dimen & 2.Dimen & Variable & 1.Dimen & 2.Dimen & Variable & 1.Dimen & 2.Dimen \\
\hline USA & 2.2765 & 0.3983 & Ireland & 0.2945 & -0.1318 & Luxembourg & -2.3159 & -0.1365 \\
Germany & 1.3632 & 0.9246 & Spain & 1.2488 & -1.2849 & Hungary & 0.3612 & 0.1811 \\
Australia & 1.2151 & -0.0147 & Israel & -0.4317 & -1.0245 & Mexico & 2.3640 & -0.0442 \\
Austria & -0.1488 & 0.1696 & Sweden & -1.2294 & 0.1628 & Norway & -0.5519 & 0.0674 \\
Belgium & -0.2539 & 0.2743 & Switzerland & -0.4628 & -0.5426 & Poland & 0.7227 & 1.1913 \\
Czech R. & -0.5045 & 0.3425 & Italy & 1.3506 & -0.9011 & Portugal & -0.0999 & -0.7540 \\
Denmark & -0.6334 & 0.7524 & Iceland & -1.9565 & -0.3866 & Chile & 0.8694 & -0.7811 \\
Estonia & -1.8965 & 0.0457 & Japan & -1.0625 & 0.9461 & Slovakia & -1.1197 & 0.0117 \\
Finland & -1.1136 & 0.1997 & Canada & 1.0248 & 1.1066 & Slovenia & -1.4051 & 0.0094 \\
France & 2.0038 & 0.0613 & S. Korea & -0.1692 & 1.2065 & Turkey & 1.8158 & -1.3152 \\
Netherlands & 0.4110 & 0.4869 & Latvia & -1.2087 & 0.0762 & Greece & 0.0476 & -1.3980 \\
Britain & 1.2929 & 0.5715 & Lithuania & -1.8598 & -0.1718 & NewZealand & -0.2381 & -0.2991 \\
\hline
\end{tabular}




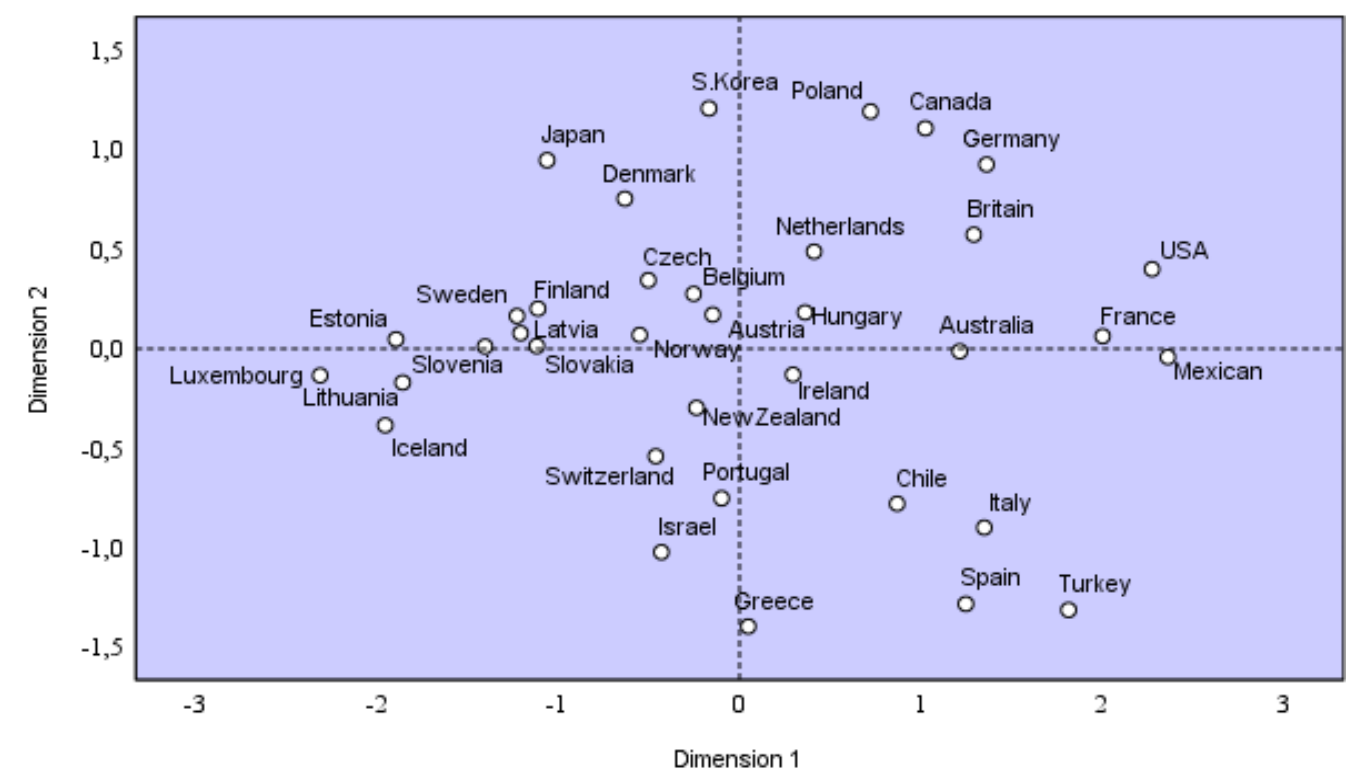

Figure 2. Configuration of $36 \mathrm{OECD}$ countries in two-dimensional space.

As seen from Figure 2; Mexico, USA, France, Turkey, Germany, Italy, UK, Spain, Australia and Canada are the most similar countries in the first dimension. These countries have positive loads and play the most important discriminator role in this dimension. Therefore, it can be expressed that these 10 countries, especially Mexico (2.3640), the USA (2.2765) and France (2.0038), have a great influence among OECD countries. Furthermore, Turkey (1.8158) seems to be high in terms of the effectiveness of the variables. With a higher impact, these countries are differentiating from the other 26 countries.

Luxembourg, Iceland, Estonia, Lithuania, Slovenia, Sweden, Latvia, Slovakia, Finland and Japan were located negative region of the first dimension with greater than 1 (numerically less than -1 ) loading values in the first dimension. Although these countries are similar to each other, they differ from the general trend since they have negative values greater than 1 . Therefore, besides having negative effects, they are not of primary importance. Especially, Luxembourg (2.3159) and Iceland (-1.9565) have high negative loads and these two countries quite different countries. According to these results, it can be stated that these 10 countries are different from other countries in the first dimension. Mexico and Luxembourg are the most different countries in the first dimension while Belgium and New Zealand are the most similar countries.

According to second dimension, Korea, Poland and Canada are similar to each other and these countries are the most important differentiators in this dimension. These countries have positive loads as well as the effect values of these loads are greater than 1 . These 3 countries can be considered to have a great influence among the OECD countries. Thus, it can be noted that these 3 countries are similar to each other and differ from the other 33 countries with higher effects in the second dimension.
In the second dimension with a negative value greater than 1, Greece, Turkey, Spain and Israel were identified as different countries. Although these countries are similar to each other, they are differed from the general trend with have negative values greater than 1 . With having a negative effect, they are not of primary importance. According to these results, it can be mentioned that these countries are different from the other 32 countries in the second dimension. In this dimension, Korea and Greece are the most different countries, while Slovenia and Slovakia are the most similar.

When considering of two dimensions together, it can be expressed that the USA, Germany, France, Netherlands, England, Canada, Hungary and Poland have positive loadings. These 8 countries had the highest effect on the livestock sector, especially the USA and France, due to their high values. On the other hand, Israel, Switzerland, Iceland, Lithuania, Luxembourg, Portugal and New Zealand have negative loadings in both dimensions. For this reason, these countries, especially Luxembourg and Iceland, are the countries that have the least effect on the livestock sector.

The stress values showing the fit between the positions of the data in multidimensional space and their positions in two-dimensional space are given in Table 3.

Iteration was continued until the correction value of the stress statistics for two dimensions $(p=2)$ reached a value less than 0.001 and the iteration was stopped when this value reached 0.00064 in the $6^{\text {th }}$ iteration. In the $6^{\text {th }}$ iteration, the stress value was found 0.13289 and this value indicted that the fit between the real positions of the data in the multidimensional space and the reduced positions in the two-dimensional space was at a moderate level. 
Besides, the stress statistics calculated by the Kruskal equation and the coefficient of determination, which is the square of the correlation coefficient, are given. Corresponding to the stress value, determination coefficient $\left(R^{2}\right)$ was found 0.88322 . This value is greater than 0.60 and indicates that the analysis is reliable.

Coordinates of the animal species in twodimensional space are given in Table 4.

Table 3. S-Stress, correction value for two dimensions by animal species; Kruskal Stress and $R^{2}$ value.

\begin{tabular}{ccccc}
\hline Iteration & S-Stress & Improvement & Stress & $R^{2}$ \\
\hline 1 & 0.18735 & - & & \\
2 & 0.14481 & 0.04255 & & 0.88322 \\
3 & 0.13747 & 0.00733 & 0.16448 & \\
4 & 0.13476 & 0.00271 & \\
5 & 0.13352 & 0.00124 & \\
6 & 0.13289 & 0.00064 & \\
\hline
\end{tabular}

Table 4. Coordinates of animal species in two-dimensional space.

\begin{tabular}{lcclccccc}
\hline Variable & 1.Dimen & 2.Dimen & Variable & 1.Dimen & 2.Dimen & Variable & 1.Dimen & 2.Dimen \\
\hline Buffalo & -0.8287 & -0.7671 & Duck & 1.5181 & -0.8634 & Mule & -1.3002 & 0.1362 \\
Cattle & 0.5165 & 0.4262 & Goat & -0.9889 & 0.4640 & Pig & 1.7400 & 0.9686 \\
Chicken & 0.5908 & 0.3664 & Goose & 0.1389 & -2.6397 & Sheep & -1.1879 & 0.2796 \\
Donkey & -1.3049 & 0.4452 & Horse & 0.4635 & 0.8823 & Turkey & 0.6427 & 0.3017 \\
\hline
\end{tabular}

According to these coordinates, locations of the animal species in two-dimensional space were visualized in Figure 3.

In the first dimension, pig and duck, which have positive and greater than 1 effect values, were determined as the most similar species. Therefore, it can be noted that these two species are similar to each other for 36 variables or countries. donkey, mule and sheep with a negative value greater than 1 in this dimension were defined as different species. Although these species are similar to each other, having negative values greater than 1 shows that they are different from the general trend. Therefore, these are species that have both negative effects and are not of primary importance. Thus, it can be considered that these 3 species are different from the other 9 species in the first dimension for the 36 variables (countries). Two most different species in this dimension are pig and donkey, while the two most similar species are donkey and mule.

In the second dimension, pig and horse are similar to each other and they are the most important discriminant in this dimension. Although these two species have less than 1 loading values, their effects are high among the given species. Goose's loading value is -2.6397 and can be defined as the most different species. Thus, it can be noted that this species is quite different from the other 11 species in the second dimension. In the second dimension, pig and goose are the most different species from each

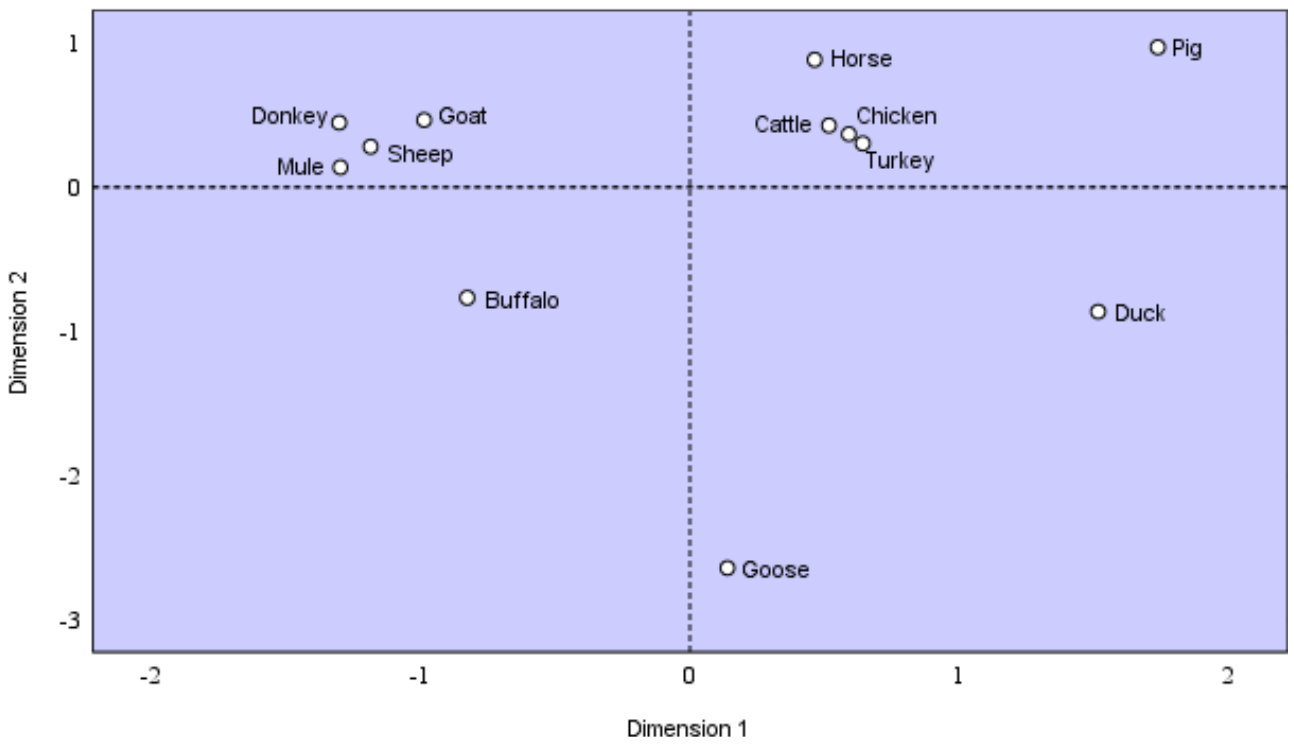

Figure 3. Configuration of animal species in two-dimensional space. 
other, while donkey and goat are the most similar species.

When two dimensions are considered together, pig, buffalo, chicken and turkey have a positive loading and the highest effect on the livestock sector. On the other hand, buffalo has a negative loading in both dimensions and has the lowest effect on the livestock sector.

In this study, by NMDS analysis, configuration of 36 OECD countries in two dimensional space was examined and similarities/dissimilarities between these countries were determined for the variables regarding with animal data. In the first dimension, Mexico, the USA, France, Turkey, Germany, Italy, UK, Spain, Australia and Canada were found quite similar to each other. It was observed that these 10 countries, especially Mexico (2.3640), the USA (2.2765) and France (2.0038), have a high level of effectiveness and differ from the other 26 countries. According to results of our study, it can be stated that Scandinavian countries are similar to each other with their positive or negative effects, However, there are quite differences between the results of previous studies for similarities/dissimilarities in the literature.

In NMDS, the relationships between objects are determined by reducing the size and converted the distance matrix into graphing coordinates, thus the method is defined as a graphical method. In this graphical representation, it is expected that the points showing similar objects in the conceptual space are close to each other while the points that are not similar to each other are far from. When determining this distance/proximity, metric or non-metric scaling method is used depending on the data structure (Everitt and Dunn, 2001; Alpar, 2011; Ding, 2018).

In MDS, generally using a two-dimensional space, the results can be better understood and interpreted. However, while applying this dimension reduction method, it is necessary to present a model close to the real structure of the objects of the representation model obtained with as little dimension as possible (Mackay and Zinnes, 1986; Tatlıdil, 1992).

NMDS has fewer assumptions than MDS. This makes it more preferable. In addition, assumptions of NMDS are also more flexible, thus it possible to obtain smaller sized solutions in NMDS (Özdamar, 2004). However, there are some uncertainties regarding its interpretation, reflection and rotation in both methods. All points in the figures can be shifted from one place to another, as well as the entire shape can be rotated or reflected. Based on this information, NMDS uses only the order of magnitude of the distances to solve it, and the ordinal numbers of the distance values constitute the only information used to determine the configuration distance values (Tatlıdil, 2002). In NMDS, analytical solution is not possible in the general algorithm. Therefore, the stress value is tried to be minimized with an iterative approach. Another problem is that the stress value decreases smoothly with increasing dimensions. This lead to difficulties to select the proper number of dimensions. Also, interpreting a spatial map containing more than three dimensions can be difficult. In this case, the stress value is minimized by an iterative method and proper dimension number (mostly as 2) is determined (Basalaj, 2001; Gündüz, 2011). Iterative methods calculated with Monte Carlo also have some disadvantages in NMDS. This method can be time-consuming in large data sets, different estimates are likely to be obtained in each iteration and the graphical representation is shaped accordingly (Alp and Gündoğdu, 2007).

Euclidean distance, which takes into account every variable and does not eliminate the excesses (repeating effects of repeated variables), is an appropriate measure when the variables are continuous and absolute distances are desired to be reflected (Seber, 2004; Giguère, 2006). Therefore, optimum distances between objects in $\mathrm{k}$ dimensional space was computed based on Euclidean distance by considering the data structure and scale type in the study. In addition, the data set was analyzed using 4 different distance measurements to show that Euclidean is better than other distance measurements. While Minkowski distance is the same as Euclidean, Manhattan distance was found close to Euclidean with a slightly higher (0.14532) Stress and slightly lower $(0.90385) R^{2}$ value, while the Chebyshev measure gives very bad values compared to Euclidean with 0.26555 Stress and $0.63594 R^{2}$ value.

Ersöz (2008) revealed the similarities or differences of OECD countries, taking into account the health level measures and health expenditure indicators. In his analysis, three groups were formed in two-dimensional space. In the first dimension, Turkey, Korea, Mexico, Poland, and Slovakia are similar for 14 variables. In the second dimension, America is differing and according to the difference matrix Turkey, Germany, Austria and Norway were showed to differ from each other. Stress value was found 0.18 as "medium fit". Especially in the first dimension, Mexico and Turkey were similar; Luxembourg and Iceland were similar, however different from the general trend. High negative value of Greece in the second dimension is consistent with our study.

Beyhan Acar (2013) investigated the similarities of OECD countries in terms of labor market key indicators. The results of the research showed that the two countries were most similar to each other. Netherlands and Belgium were differing from each other as well as Slovakia and Iceland. Besides, Turkey was different from all other countries. Spain was the most different country from Iceland.

Boz et al. (2016) examined the similarities of OECD countries in terms of health system indicators and stated that Turkey, Mexico, Chile and Korea were quite similar for considered variables. However, Turkey was quite different from Greece, the USA, Switzerland, Portugal, Australia, Spain and Japan. Akdamar (2019) found "good fit" for two dimensions in terms of labor market indicators of OECD countries and Turkey as well as Greece and Spain were found different from other OECD countries. 
Akın and Eren (2012) revealed the similarities of OECD countries in terms of education indicators. They found that the fit level was "very good" with 0.03058 stress value. In the first dimension, Mexico, Sweden, Germany and France were found quite similar to each other with negative values. Other countries, except Turkey, were located at the same region with a high positive value. Turkey seemed to be quite different from these countries in this dimension. In the second dimension, Denmark and Norway with a positive value and Korea and Chile with a negative value were quite different from other countries.

Çankaya et al. (2003) used MDS to explain the similarities or dissimilarities between 21 morphological characters of 6 honeybee genotypes collected from different regions of Turkey. The results showed that the selected genotypes fit each other perfectly from the examined morphological characters.

Çelik (2015) examined the similarities of 81 provinces in Turkey in terms of livestock data using the data of 2014 with MDS analysis. According to the results of the analysis, it has been determined that Şırnak, Antalya, Siirt and Bitlis are different from other provinces, and that Tunceli, Hakkari, Van, Şanlıurfa, Siirt, Bitlis and Şırnak provinces are the provinces that have the most positive impact on animal production in Turkey. Similarly, Kandemir et al. (2019) were examined the similarities of 12 statistical regions in Turkey in terms of sheep and mutton prices by MDS. As a result, the differences of the regions from each other have been revealed and it has been emphasized that the carcass meat price is high in the regions where the number of sheep is high.

On the other hand, Güler (2021) examined the similarities of 24 regions in terms of silkworm breeding with MDS analysis by using 2019 data about number of enterprises (households), silkworm breeding, the number of opened boxes and the amount of fresh cocoon production. As a result, the author noted that the region that contributed the most to silkworm breeding was the TRC2 (Şanlıurfa and Diyarbakır) region, and the region that contributed the least was the TRA1 (Erzurum, Erzincan and Bayburt) region. The author also indicated that TR51 (Ankara), TR32 (Aydın, Denizli and Muğla), TR41 (Bursa, Eskişehir, Bilecik) and TR42 (Kocaeli, Sakarya, Düzce, Bolu and Yalova) regions are similar to each other in terms of silkworm breeding.

\section{Conclusion}

In the study, the coefficient of determination was found $91 \%$ and it can be stated that MDS can be used as an effective method for visualization of the similarities between OECD countries in terms of animal species in two-dimensional space. When two dimensions are considered together, it can be stated that Turkey shows similarities with Spain, Italy, Chile, Ireland, and Greece among OECD countries in terms of animal species.
On the other hand, Turkey is differing from 13 countries that Korea, Japan, Denmark and Estonia. According to the two dimensions, animal's species can be clustered into 3 groups: duck and goose in group 1; horse, pig, cattle, chicken and turkey in group 2; and donkey, mule, sheep and goat in group 3.

As a result, it is important to determine the animal species raised in the countries with similar culture and nature for planning of short, medium and longterm livestock programs and investments of the countries. In this context, the study may contribute to the literature.

\section{References}

Ağgün, F. (2011). Investigating of multidimensonal scaling analysis and an application [Unpublished Master Thesis]. University of Yüzüncü Yıl.

Akdamar, E. (2019). Investigation of the OECD countries by using some labor market indicators with cluster analysis and multi-dimensional scaling analysis. Journal of Academic Researches and Studies, 11(20), 50-65.

Akın, H. B., Eren, Ö. (2012). OECD countries with education indicators comparative analysis of cluster analysis and multi-dimensional scaling analysis. Öneri Journal, 10(37), 175-181.

Alp, S., Gündoğdu, C. E. (2007). Ceza mahkemelerinin dava sayılarının görev ayırımı ve coğrafi bölgelere göre dağılımlarının monte carlo simülasyonu kullanılarak tahmin edilmesi. Uludağ Üniversitesi İktisadi ve İdari Bilimler Fakültesi Dergisi, 26, 55-68.

Alpar, R. (2011). Uygulamalı çok değişkenli istatistiksel yöntemler. Detay Yayıncılık, Ankara.

Basalaj, W. (2001). Proximity visualisation of abstract data. University of Cambridge, United Kingdom.

Beyhan Acar, A. (2013). Comparison of Turkey and the other oecd countries in terms of labour markets' main indicators using multidimensional scale analysis. i.ü. İşletme Fakültesi İşletme îktisadı Enstitüsü Yönetim Dergisi, 24(75), 121-144.

Borg, I., Groenen, P. J. F. (2005). Modern multidimensional scaling theory and applications. springer, New York.

Borg, I., Groenen, P. J. F., Mair, P. (2018). Applied multidimensional scaling and unfolding. Springer, Rotterdam.

Boz, C., Sur, H., Söyük, S. (2016). The similarities and differences analysis of oecd countries in terms of health system indicators. ACU Sağlık Bilimleri Dergisi, 3,154-164.

Cox, T. F., Cox, M. A. A. (2001). Multidimensional scaling. Chapman Hall/CRC, New York.

Çankaya, S., Kayaalp, G. T., Önder, H. (2003). Use of multidimensional scaling analysis in animal science. The Second International Biometric Society Confererence of The Eastern Mediterranean Region, Antalya, Turkey, 12-15 Ocak 2003, 75-80. 
Çelik, Ş. (2015). Classification of provinces in turkey in terms of livestock using multidimensional scaling analysis. Erciyes University Journal of Institute of Science and Technology, 31(4), 159-164.

Ding, C. S. (2018). Fundamentals of applied multidimensional scaling for educational and psychological research. Springer, Cham.

Ersöz, F. (2008). Analysis of health levels and expenditures of Turkey and OECD countries. İstatistikçiler Dergisi, 2, 95-104.

Everitt, B., Dunn, G. (2001). Applied multivariate data analysis. John Wiley \& Sons, Chichester.

FAO. (2020). Food and agriculture organization of the United Nations. http://www.fao.org/faostat /en/\#data /QA (2020, February 5).

Giguère, G. (2006). Collecting and analyzing data in multidimensional scaling experiments: A guide for psychologists using SPSS. Tutorials in Quantitative Methods for Psychology, 2(1), 26-37.

Güler, D. (2021). Investigation of the sericulture in Turkey by multidimensional scaling and cluster analyses. KSU J. Agric Nat, 24 (1), 212-220.

Gündüz, S. (2011). Investigation of effects on multidimensional scaling algorithms of distance functions and applications [Unpublished Master Thesis]. Çukurova University.

Härdle, W. K., Simar, L. (2015). Applied multivariate statistical analysis. Springer, Heidelberg.

IBM Corp. Released (2012). IBM SPSS statistics for windows, version 21.0. Armonk, NY: IBM Corp.,
Johnson, R. A., Wichern, D. W. (2007). Applied Multivariate Statistical Analysis. Prentice Hall, New Jersey.

Kandemir, Ç., Adanacıoğlu, H., Taşkın, T., Koşum N. (2019). Comparison with multidimensional scale analysis by regions of live sheep and mutton prices in Turkey. Journal of Tekirdag Agricultural Faculty, 16(2), 315-327.

Kruskal, J. B. (1964). Multidimensional scaling by optimizing goodness of fit to a nonmetric hypothesis. Psychometrica, 29(1), 1-27.

Kruskal, J. B., Wish, M. (1978). Multidimensional scaling. Sage Publications, California.

Mackay, D. B., Zinnes, J. L. (1986). A probabilistic model for the multidimensional scaling of proximity and preference data. Marketing Science, 5, 325-344.

Mead, A. (1992). Review of the development of multidimensional scaling methods. The Statistician, 41, 27-39

Özdamar, K. (2010). Paket programlar ile istatistiksel veri analizi-2 (çok değişkenli analizler). Kaan Kitapevi, Eskişehir.

Seber, G. A. F. (2004). Multivariate observations. John Wiley \& Sons, New Jerse.

Takane, Y., Young, F.W., De Leeuw, J. (1977). Nonmetric individual differences multidimensional scaling: An alternating least squares method with optimal scaling features. Psychometrıka, 42(1), 7-67.

Tatıdil, H. (1992). Uygulamalı çok değişkenli istatistiksel analiz. Akademi Matbaası, Ankara. 